\title{
CONEXÕES E DISJUNÇÕES NO DIÁLOGO ENTRE O ROMANCE E A FILOSOFIA: SABEDORIA DA INCERTEZA, VERDADE E LIBERDADE
}

\author{
Connections and disjunctions in the dialogue \\ between the novel and philosophy: wisdom of \\ uncertainty, truth and freedom
}

\author{
Heraldo Aparecido Silva*
}

\begin{abstract}
RESUMO
Este artigo tem por objetivo analisar alguns aspectos da relação entre o romance e a filosofia a partir das ideias do romancista tcheco Milan Kundera e do filósofo norte-americano Richard Rorty. Primeiro, mostramos que o advento dos tempos modernos pode ser atribuído não somente a Descartes, mas também a Cervantes. Nessa perspectiva, a noção de romance como sabedoria da incerteza é evidenciada para se contrapor à obsessiva busca filosófica pela verdade absoluta. Finalmente, a partir da discussão contemporânea sobre as funções sociais da teoria e a narrativa, destacamos que as transformações sociais mais relevantes são ocasionadas principalmente pela sensibilidade e imaginação literárias mais do que pela argumentação filosófica.
\end{abstract}

Palavras-chave: romance; filosofia; literatura.

\begin{abstract}
The aim of this article is to analyze some aspects of the relationship between novel and philosophy from the ideas of Czech novelist Milan Kundera and the American philosopher Richard Rorty. First, it shows that the advent of modern times can be

* Universidade Federal do Piauí (UFPI).
\end{abstract}


attributed not only to Descartes, but also to Cervantes. From this perspective, the notion of novel as wisdom of uncertainty is evident to counteract obsessive philosophical quest for $a b$ solute truth. Finally, from the contemporary discussion about the social functions of theory and narrative, we highlight that most of the relevant social changes are mainly caused by the sensitivity and literary imagination, rather than by philosophical argument.

Keywords: novel; philosophy; literature.

Neste texto, analisaremos alguns aspectos da relação entre a literatura e a filosofia a partir das idéias do romancista tcheco Milan Kundera e do filósofo americano Richard Rorty. Primeiramente, nos deteremos na obra $A$ arte do romance (1988), de Kundera; depois, centraremos nossa atenção em alguns artigos de Rorty que, conforme acreditamos, relacionam-se com a perspectiva kunderiana de romance. Os artigos rortyanos aos quais nos referimos são os seguintes: Truth and Freedom: a reply to Thomas McCarthy (1990), The Inspirational Value of Great Works of Literature (1997) e Heidegger, Kundera, and Dickens (1995). Finalmente, apresentaremos uma perspectiva que procura mediar a tensão entre a teoria (os sistemas filosóficos) e a narrativa (romances), equiparando-as como instrumentos ad hoc, torneáveis para a realização de propósitos específicos, seja para a transformação social ou para a autocriação humana.

No ensaio A Arte do romance, constituído por textos e entrevistas, Milan Kundera expõe a sua idiossincrática concepção de romance. Na perspectiva kunderiana a tradicional distinção entre literatura e filosofia torna-se obsoleta à medida que contestamos a primazia do saber científico-filosófico sobre o saber romanesco. Na primeira parte, intitulada $A$ herança depreciada de Cervantes ele nos adverte sobre a possibilidade do romance ter assumido um propósito originalmente filosófico: a paixão de conhecer. Este propósito, teria sido inaugurado pela abrangente filosofia grega antiga e abandonado pela restringente filosofia europeia moderna (DESCARTES, 1983).

A partir de Descartes, a epistemologia tornou-se uma das áreas centrais da filosofia, visto que os temas práticos e sapienciais da filosofia greco-romana e os temas espirituais e teológicos da filosofia medieval, cederam seus lugares para temas relativos especificamente ao conhecimento. A origem dessa mudança está localizada na proposta cartesiana, conhecida como epistemologia representacionista, de se conceber a mente humana como uma espécie de espelho no qual estaria refletida a imagem da natureza (DESCARTES, 1983). Através dessa forma representacional de conceber a realidade, o acesso ao conhecimento estaria assegurado pela mente humana, 
pois o conhecimento objetivo seria propriedade de uma essência especular, uma capacidade comum a todos de espelhar a natureza. Desse modo, a filosofia deixa de ser a primordial busca pela sabedoria para se tornar uma atividade voltada para a busca pela verdade e fundamentação do conhecimento. Como veremos posteriormente, essa perspectiva cartesiana é combatida pelo pragmatismo porque eles desvirtuam e até mesmo impedem a realização da filosofia como conversação, isto é, como uma atividade prática e sapiencial que visa a edificação das pessoas (RORTY, 1994).

Assim, Kundera acredita que toda análise sobre a modernidade que não leve em consideração o romance é lacunar e equivocada. Isto porque, na sua opinião, "o fundador dos Tempos Modernos não é somente Descartes mas também Cervantes"; e também porque se no início da modernidade "a filosofia e as ciências esqueceram o ser do homem", negligenciando os temas existenciais, o romance formou-se essencialmente para explorar, à sua maneira, "esse ser esquecido" (KUNDERA, 1988, p. 10). Neste sentido, a concepção kunderiana de romance parte do pressuposto de que o romance deve descobrir alguma faceta até então desconhecida da existência. A busca por esse conhecimento que somente o romance pode descobrir é a sua única moral.

Entretanto, é preciso notar que na concepção kunderiana, temos o acréscimo e a ressalva que, o aspecto gnosiológico das obras romanescas deve, necessariamente, estar sob a égide estética: a beleza não é apenas um aspecto complementar do conhecimento mas, um elemento essencial e indissociável à própria estrutura do romance, que é conhecimento e beleza. Este sentido estético permite divisar os limites entre a filosofia e a ciência, por um lado, e o romance, por outro.

Assim, o conhecimento estaria, de certo modo, submetido à beleza, pois é ela que possibilita ao romance ser paradoxal: o romancista - independentemente de trabalhar com itens reais ou imaginários - pode transformar holocaustos e hediondas tragédias pessoais em sublimes experiências existenciais. Se tais relatos não contivessem esta inédita dimensão estética (o belo, o feio, o grotesco e o sublime), não seriam romance e não conteriam a sabedoria do romance; seriam outros tipos de relatos, cujas informações descritivas nada acrescentariam ao conhecimento além do já sabido: houve destruição e morte, terror e dor. Logo, o romance ainda acrescenta isto: houve também a beleza - que desperta nosso interesse e nos faz desejar saber mais. Esta paradoxalidade é combatida pela filosofia e pela ciência pois, para elas os paradoxos representam perigo: ameaçam dissolver com a sua ambiguidade as bases sobre as quais as mesmas são erigidas: a verdade, a objetividade, a certeza e a causalidade. Portanto, "todos os aspectos da existência que o romance descobre, ele os descobre como beleza" (KUNDERA, 1988, p. 110). 
Retornando ao gládio filosofia versus romance, notamos a diferença entre a disjuntiva perspectiva filosófica que estabelece alternativas e a conjuntiva perspectiva romanesca que estabelece relação entre as coisas; evidenciada pelo seguinte trecho:

Quando Deus deixava lentamente o lugar de onde tinha dirigido o universo e sua ordem de valores, separado o bem do mal e dado um sentido a cada coisa, Dom Quixote saiu de sua casa e não teve mais condições de reconhecer o mundo. Este, na ausência do Juiz Supremo, surgiu subitamente numa temível ambigüidade; a única Verdade divina se decompôs em centenas de verdades relativas que os homens dividiram entre si. Assim, o mundo dos Tempos Modernos nasceu e, com ele, o romance, sua imagem e modelo. (KUNDERA, 1988, p. 12).

O que é evidenciado aqui é, principalmente, uma diferença crucial entre as visões de Descartes e Cervantes acerca da modernidade. Enquanto que o filósofo francês compreendia que o fundamento de tudo era o ego pensante, o romancista espanhol percebia o mundo como ambigüidade (DESCARTES, 1983; CERVANTES, 1998). Por conseguinte, enquanto Descartes sentiu-se legitimado para trilhar o caminho da busca pela verdade distinta e segura, Cervantes teve que "que afrontar, ao invés de uma só verdade absoluta, um monte de verdades relativas que se contradizem (verdades incorporadas em egos imaginários chamados personagens)" e, neste caso, possuir como "única certeza a sabedoria da incerteza" (KUNDERA, 1988, p. 12). Desta forma, podemos compreender que o campo romanesco é habitado por exceções e não por regras.

o homem deseja um mundo onde o bem e o mal sejam nitidamente discerníveis, pois existe nele a vontade inata e indomável de julgar antes de compreender. Sobre essa vontade estão fundadas as religióes e as ideologias. Elas não podem se conciliar com o romance a não ser que traduzam sua linguagem de relatividade e ambigüidade no próprio discurso apodítico e dogmático. Elas exigem que alguém tenha razão [...]. (KUNDERA, 1994, p. 12-13).

Nessa perspectiva, com exceção da literatura, as demais áreas do saber humano, acrescidas das religiões e das ideologias, são incapazes de resistir a relatividade essencial das coisas humanas e, por isso, não conseguem - ou não querem - aceitar e compreender a sabedoria do romance, também denominada paradoxalmente de sabedoria da incerteza - aliás, a única certeza da qual o romance é possuidor.

E se própria existência do romance finda quando ele deixa de cumprir o seu papel de descobrir novas possibilidades da existência humana, então, qual é o limite da sabedoria do romance? Ou ainda: qual é a extensão 
de seu conhecimento? O romance pode até estar próximo do fim - dada a sua incompatibilidade com o mundo atual - mas está longe de ter esgotado as suas possibilidades: afinal, tanto na composição quanto no desenvolvimento de temas, podemos encontrar linhas não exploradas e abandonadas pelos romances ulteriores (KUNDERA, 1988, p. 18-19).

Desse, modo, em torno desse aspecto investigativo dos romances, temos a explicação de que toda obra romanesca, sem exceção, é uma incessante busca por respostas para o ontológico enigma do eu. Neste caso, os personagens ou egos experimentais caracterizam hipóteses, tentativas de solução à interrogação existencial primeva. E diante da impossibilidade de se atingir o eu, a busca por si só é suficientemente válida por tentar revelar os inauditos limites das possibilidades romanescas.

Diante da questão sobre a possibilidade dos romances kunderianos serem filosóficos, a resposta é que tal comparação é improcedente, visto que a filosofia e o romance desenvolvem seus temas em contextos distintos: ao contrário do romance, "[a] filosofia desenvolve seu pensamento num espaço abstrato, sem personagens, sem situações” (KUNDERA, 1988, p. 31). E, além disso, a perspectiva kunderiana exara entusiasticamente que o "romance conhece o inconsciente antes de Freud, a luta de classes antes de Marx, ele pratica a fenomenologia (a busca da essência das situações humanas) antes dos fenomenólogos" (KUNDERA, 1988, p. 34).

Aqui é apropriado recordar que o processo de filosofar não é dogmático, já que admite diferentes estilos de expressão textual, tais como o diálogo, o ensaio, o aforismo, a carta, o tratado, o poema e a confissão (MARCONDES; FRANCO, 2011). Embora a maior parte dos filósofos que tenham feito uso de fragmentos poético-filosóficos sejam pré-socráticos, alguns filósofos contemporâneos também fizeram uso da poesia e da literatura como exemplos de atividade criativa ou de expressão de novos pensamentos (PRADO JÚNIOR, 2000; BAGGINI; FOSL, 2008). Nietzsche escreveu um de seus mais famosos livros, o Assim falou Zaratustra, na forma de uma extensa poesia. Heidegger, por sua vez, em diversas vezes, conectou suas investigações filosóficas com aquilo que ele chamava de dizeres essenciais de alguns poetas como Hölderlin e Rilke (CICERO, 2012). Além disso, filósofos como Rousseau, Diderot e Voltaire também escreveram romances filosóficos influentes: respectivamente, Emílio, O sobrinho de Rameau e Cândido. Além disso, diversos filósofos contemporâneos, dentre os quais Adorno, Benjamin, Sartre, Foucault, Deleuze e Rorty utilizaram elementos literários como objeto de seus estudos ou, ainda, como inspiração para a elaboração de ferramentas conceituais críticas.

Ainda em torno da distinção entre a filosofia e o romance, suas respectivas estruturas fundamentais são evidenciadas nos seguintes termos: 
enquanto que as reflexões filosóficas são elaboradas no campo das afirmações, as reflexões e digressões romanescas são compostas no domínio do jogo e das hipóteses. Tais características constitutivas estabelecem a filosofia e a arte em regiões semânticas opostas, pois, quando os romancistas "exprimem diretamente suas idéias, em seus apontamentos, estas são mais exercícios de reflexões, jogos de paradoxos, improvisações que a afirmação de um pensamento" (KUNDERA, 1988, p. 72-73). Além disso, inversamente do que ocorre no discurso filosófico, o discurso romanesco despoja o autor de sua primazia assertiva, visto que, no romance, há um nexo inexorável entre a reflexão e o ego experimental: meditações, afirmações e negações são feitas através de personagens. Outra peculiaridade distintiva concerne ao tratamento dos temas abordados: se na filosofia o tema é secundário, no romance ele é subjugante, pois é sempre perspectivado como uma interrogação existencial.

Outro elemento destacado para tratar das diferenças entre a filosofia e o romance é a ironia. Assim, embora a menção aos nomes de Sócrates, Schlegel, Kierkegaard, Voltaire e Rorty, dentre outros, seja suficiente para asseverar que a ironia não é estranha à filosofia, devemos recordar também que a referida figura de linguagem foi repudiada pela restritiva Filosofia Moderna obcecada com a verdade objetiva. Inversamente, na mesma épo$\mathrm{ca}$, o romance surge como uma arte irônica, interessado naquelas outras verdades que margeiam o inefável e o indizível. Podemos considerar que a "ironia irrita" os filósofos com pendores cientificistas não porque ela "zombe ou ataque, mas porque nos priva das certezas, desvendando o mundo como ambigüidade" (KUNDERA, 1988, p. 119).

Assim, a fim compreender o advento da modernidade, não deveríamos considerar apenas a vertente filosófica do século XVIII, mas também - e principalmente - a vertente romanesca pois, se Rousseau, Voltaire e Holbach retrataram a sua época; Fielding, Sterne, Goethe, e Laclos também o fizeram, propiciando que a filosofia e o romance travassem, de forma indireta, um profícuo diálogo. Essa conversação enviesada deve-se ao fato de ambos, filosofia e romance, terem partido de premissas opostas na modernidade: enquanto a vertente filosófica, aliada da ciência, concebia o mundo como causalidade; a vertente romanesca, juntamente com a poesia, o entendia como possibilidade. Por conseguinte, se a filosofia busca um fundamento que justifique cada ação humana; o romance renuncia a este propósito.

A erudição de Rabelais, por maior que seja, tem portanto um outro sentido que a de Descartes. A sabedoria do romance é diferente daquela da filosofia. O romance nasceu não do espírito teórico mas do espírito do humor. [...] A arte inspirada pelo riso de Deus é, por sua essência, não tributária mas contraditória das certezas 
ideológicas. A exemplo de Penélope, ela desfaz durante a noite a tapeçaria que os teólogos, os filósofos, os sábios urdiram na véspera. (KUNDERA, 1988, p. 141).

Portanto, a conclusão é que não podemos "julgar o espírito de um século exclusivamente segundo suas idéias, seus conceitos teóricos, sem levar em consideração a arte e especialmente o romance" (KUNDERA, 1988, p. 143).

Esta conclusão kunderiana repercute nas palavras do filósofo pragmatista Rorty, principalmente, nos artigos Truth and Freedom: a reply to Thomas McCarthy (1990), Heidegger, Kundera, and Dickens (1995) e The Inspirational Value of Great Works of Literature (1997). Como afirmamos no início deste artigo, os textos filosóficos elaborados por Rorty são, segundo suas próprias palavras, um produto de sua reação a determinados livros de outros autores. Assim, a respeito de Art of Novel, é importante notar que o filósofo neopragmatista descrevera-o como um de seus livros favoritos, a partir do qual, inclusive, extrai uma passagem para usar como epígrafe de sua obra Contingência, Ironia e Solidariedade (RORTY, 1994, p. 106). Logo, dedicaremos o restante deste artigo para a análise da reação do filósofo norte-americano a esta obra. A seqüência a seguir, obedece a ordem cronológica original da publicação dos textos.

Em Truth and Freedom: a Reply to Thomas McCarthy Rorty (1990) posiciona-se a respeito das duas noções que nomeiam seu artigo conclamando a fixar a liberdade e esquecer da verdade e da racionalidade. Esta afirmação pode ser melhor compreendida se for complementada com algumas das considerações sobre o etnocentrismo, haja vista que, para Rorty, a verdade é algo obtido como o resultado de encontros livres e abertos e a racionalidade é obtida quando se substitui a força pela persuasão. Sobre a idéia de fixar a liberdade, resta dizer que a mesma deve ser entendida em conformidade com a argumentação antifundacionista rortyana, ou seja, não se trata de encontrar ou estabelecer uma noção exclusiva e universal de Liberdade; mas sim, trata-se de eleger como princípio norteador a liberdade - histórica, local e contingente - e se esforçar para expandi-la a outras comunidades.

Assim como Kundera, Rorty também pensa que a filosofia, a partir da modernidade, delimitou demasiadamente a sua temática quando centrou seu interesse na discussão acerca da verdade. Desde então, a filosofia teria se distraído - conforme o termo usado por Kundera - amplamente em relação a busca pela liberdade e, portanto, como conseqüência dessa negligência ela deve ser considerada como de pouca utilidade para a investigação sobre como ampliar liberdades. Em contrapartida, uma alternativa útil seria configurada por descrições revigorantes que, na acepção rortyana, é o que de fato funciona para criar liberdades ou expandir liberdades já existentes a fim de abarcar pessoas ou comunidades que anteriormente não eram lembradas ou privilegiadas. 
Aqui, é importante notar que há uma interdependência entre as sugestóes concretas e o seu propósito, a saber, a ampliação das liberdades: isto porque, além das referidas sugestões, Rorty também condiciona o progresso moral e intelectual a fatores como boa sorte, liberdade cultural e liberdade política. Em outras palavras, quanto mais liberdade tivermos mais poderemos fazer - se formos afortunados - para ampliá-la a fim de que atinja outras culturas. É perceptível que a realização deste propósito, mediante narrativas inspiradoras e sugestões concretas, depende cada vez mais de sociedades cujos sistemas políticos garantam liberdade de expressão aos seus membros para que eles possam divulgar, sem impedimentos ou constrangimentos, as imaginadas alternativas diferentes e quiçá melhores.

Isto posto, é preciso mencionar que McCarthy (1990), teórico influenciado pela tradição neomarxista da Escola de Frankfurt (notabilizada no campo da filosofia social e política pela formulação de uma teoria crítica da sociedade e da cultura a partir da análise de temas como: ideologia, ciência e técnica, progresso e violência, racionalidade instrumental, indústria cultural, controle e dominação social versus emancipação, na primeira geração com Horkheimer, Adorno, Benjamin; e crítica aos procedimentos de legitimação ética e social nos em distintos contextos de ação comunicativa, na segunda geração, com Habermas), conecta tanto a liberdade cultural quanto a liberdade política às noções de validade transcultural que, segundo ele, seriam verificáveis ao redor de toda nossa cultura, uma vez que esta estaria estruturada em tais noções. Inversamente, Rorty (1990), filósofo vinculado ao pragmatismo (notabilizado como uma filosofia da ação avessa à mera contemplação praticada pela filosofia tradicional e que sempre privilegiou temas voltados para questões práticas em política, sociedade e educação, no período clássico, com Peirce, James e Dewey; e questões acerca da linguagem e da cultura, no período contemporâneo, com Quine, Davidson e Rorty) diz que esta crença nutrida por McCarthy caracteriza uma espécie de deformação profissional dos professores de filosofia que, desde Descartes, são continuamente tentados a sustentá-la.

Isso porque, para o neopragmatista, o filósofo não é o guardião do saber e tampouco existe algo que transcenda a cultura humana, que é local, contingente, histórica e sempre passível de transformações. A esperança de Rorty é que essa tentação filosófica de busca por uma verdade transcendental esvaeça e seja substituída por uma profícua busca por formas alternativas de ser humano e que a cultura torne-se gradualmente baseada em torno da noção de liberdade, entendida como uma idéia em aberto, que permita às pessoas sonharem, pensarem e viverem como quiserem, desde que não causem dor (física ou moral) a outras pessoas. 
Neste momento, Rorty (1990) reconhece a existência de um equilíbrio argumentativo tanto na teoria quanto na narrativa, ou seja, aqueles que lutam para ampliar as liberdades individuais têm à sua disposição os mesmos recursos que aqueles que tentam tolher as mesmas. Em outras palavras, as faculdades da razão, do entendimento, do gosto e da imaginação, assim como as ferramentas conceituais de argumentação, avaliação e crítica como a lógica, a retórica, a maiêutica e a dialética estão à disposição de qualquer pessoa, tanto para o exercício da opressão quanto para a prática da liberdade (BAGGINI; FOSL, 2008).

A diferença, segundo Rorty (1990), é que nas teorias temos a pressuposição de que a cultura está estruturada plenamente por noções de validade transculturais; ao passo que, nas narrativas parte-se do princípio de que a cultura não está plenamente estruturada desta forma. A escolha de Rorty, implicitamente, baseia-se na esperança que nutre pela capacidade imaginativa dos seres humanos: como no segundo caso as possibilidades descritivas e os elementos a serem evocados são maiores - uma vez que elas não são limitadas previamente por nada-, ele espera que afortunadamente, as pessoas vislumbrem ou desejem utopias e não distopias.

Segundo Rorty, a nossa cultura não está estruturada em toda parte pela noção de validade - como afirma McCarthy - mas somente em alguns lugares. Deste modo, a sua argumentação apela justamente "para coisas que são ditas e feitas" nesses outros lugares; ou seja, ele joga alguns elementos de nossa cultura contra outros porque acredita que através deste embate, a utilidade relativa de uns sobre os outros para os propósitos humanos poderá ser melhor explicitada. Este procedimento assume que a cultura em geral é nutrida tanto por elementos que estão estruturados em torno de "noções transculturais de validade" - como as religiões, a filosofia e a ciência - quanto por elementos que não se baseiam em tais noções, como por exemplo o romance (RORTY, 1990, p. 637-638). Ele escreve:

O romance não oferece um argumento dentro do mesmo espaço dialético que previamente ocupamos, mas oferece antes um vislumbre de outros espaços. O desejo de redescrever, cultivado pela leitura dos romances, é diferente do desejo de demonstrar, cultivado pelas leituras metafísicas (RORTY, 1990, p. 640).

A flexibilidade e abrangência do romance, expressas na sua singular capacidade de assumir a totalidade das perspectivas possíveis configura o aspecto de maior dificuldade de aceitação. Entretanto, a filosofia também possui um aspecto de difícil aquiescência - principalmente por parte de poetas e romancistas -, isto é, a sua capacidade de "formular axiomas dos quais se possa deduzir e vocabulários para expressar, uma 
apologia de qualquer coisa que se goste (a escravidão, a inquisição, a democracia burguesa, os nazistas, a revolução cultural)" (RORTY, 1990, p. 641).

Em linhas gerais, podemos asseverar que o conflito entre a teoria e a narrativa é exacerbado ao assumirmos a perspectiva que concebe os sistemas filosóficos e os romances como ferramentas e, como tais, passíveis de serem moldadas para exercerem funções específicas.

Dessa maneira, embora quaisquer recursos argumentativos estejam igualmente disponíveis para os dois lados de uma contenda, Rorty (1994) acredita que atualmente devemos optar pelas narrativas em detrimento das teorias. Isto, não porque uma seja inferior a outra, ou porque haja alguma posição teórica inválida ou indefensável, mas sim porque ele considera que para a realização de muitos dos propósitos humanos contemporâneos - principalmente nas comunidades democráticas liberais -, as narrativas romanescas e jornalísticas (entre outras) têm propiciado idéias contextualmente mais úteis, no sentido de explicitarem diversos detalhes sórdidos e de terem sido historicamente mais eficazes para a promoção do bem-estar social, agindo como reguladoras e criticas das atividades políticas.

Neste sentido, Rorty sustenta que a política deve ser concebida antes como uma "experiência" do que como uma "disciplina teórica", uma vez que não é necessária nenhuma "noção teórica" para se identificar casos de egoísmo, preconceito e opressão em todo o mundo. E também, porque para modificar este quadro não é preciso de mais teoria - que já teria cumprido o seu indispensável papel para o "progresso moral e político" através de noções como "direitos do homem" e "mais-valia" - mas sim, seriam necessárias mais "utopias concretas" e "propostas concretas" como as encontradas, entre outros gêneros literários, nos romances e textos jornalísticos (RORTY, 1990, p. 640-642).

Para Rorty, embora as propostas encontradas nos textos de filósofos e teóricos sociais devam ser consideradas, as mesmas não são tão imaginativas quanto aquelas verificadas nos gêneros literários supracitados que, por esta razão, devem ser privilegiados. Se a questão prioritária não é mais desvendar a verdade e sim buscar novos meios através dos quais a liberdade possa ser gradualmente ampliada e expandida (ou mesmo suprimida; o que serviria de alerta); então, devemos nos ater principalmente ao esforço literário de invenção de novas possibilidades. Além do reconhecimento da contingência que afeta a realidade e a humanidade, este procedimento pragmático implica na invenção de novos instrumentos, novos vocabulários, novos jogos de linguagem e novas descrições e redescrições de pessoas e do mundo. Segundo Rorty, uma grata conseqüência acarretada por esta mudança de perspectiva pode ser descrita da seguinte maneira: 
A questão ‘o que é a verdade sobre nossa sociedade?' dissolver-se-á em favor de questões tais como: 'o que fará mais pessoas dessa sociedade alcançar mais liberdade?' [...]. A questão 'este valor é interculturalmente válido?' dissolver-se-ia em favor da questão: 'como podemos nos certificar de que a discussão de valores alternativos é tão livre, aberta e imaginativa quanto possível?' (RORTY, 1990, p. 643).

No texto Heidegger, Kundera and Dickens, Rorty afirma que a sua opção pela narrativa e não pela teoria, deve-se ao fato de que "os filósofos ocidentais ainda mostram uma lastimável tendência para o essencialismo quando oferece[m] comparações interculturais" (RORTY, 1995, p. 67). Assim, a fim de evitar esta infeliz tendência filosófica ele prefere teorizar cada vez menos a respeito dos ideais que defende para, em contrapartida, apontar para casos particulares - personagens, situações, temas e acontecimentos expressos em romances que ilustrem exemplarmente a forma que as coisas assumem quando tais ideais são colocadas em prática ou, ao contrário, quando são negligenciados. Esta alternativa é, conforme seu relato, baseada na sugestão kunderiana de que o romance "é o gênero característico da democracia, o gênero mais proximamente associado com a luta pela liberdade e igualdade" (RORTY, 1995, p. 67-68).

Para Rorty, a importância relativa da teoria e da narrativa para as sociedades pode ser pensada nos seguintes termos: se mensurássemos as parcelas de "bem e mal" produzidas tanto por "teóricos sociais" quanto por "romancistas sociais", nós desejaríamos que "tivesse havido mais romances e menos teorias" (RORTY, 1995, p. 80). Isto porque, no Ocidente, "nossa consciência e nossa sensibilidade" frente aos dramas e tragédias de outras pessoas são devidas mais aos esforços de romancistas como Orwell e Dickens do que de filósofos como Platão e Marx. A explicação rortyana resume-se a constatação de que os romancistas, mais do que os filósofos ou os poetas, "são bons em detalhes (RORTY, 1995, p. 81). Entretanto, como ele próprio observa no texto The Inspirational Value of Great Works of Literature, é justamente a exposição - às vezes inédita - destes detalhes que capacitam as grandes obras literárias a inspirar, em épocas distintas, inúmeras pessoas que terminam por recontextualizarem e reformularem as suas crenças (RORTY, 1997). 


\section{REFERÊNCIAS}

BAGGINI, Julian; FOSL, Peter S. As ferramentas dos filósofos: um compêndio sobre conceitos e métodos filosóficos. Tradução de Luciana Pudenzi. São Paulo: Loyola, 2008.

CERVANTES SAAVEDRA, Miguel de. Dom Quixote (volume 1). Tradução de Almir de Andrade e Milton Amado. São Paulo: Publifolha, 1998.

CICERO, Antonio. Poesia e filosofia. Rio de Janeiro: Civilização Brasileira, 2012.

DESCARTES, René. Discurso do Método, Meditações. 3.ed. Tradução de J. Guinsburg e Bento Prado Júnior. São Paulo: Abril Cultural, 1983.

KUNDERA, Milan. A arte do romance (ensaio). Tradução de Teresa Bulhões C. da Fonseca e Vera Mourão. Rio de Janeiro: Nova Fronteira, 1988.

. Os testamentos traídos (ensaios). Tradução de Teresa B. C. da Fonseca e Maria L. N. Silveira. Rio de Janeiro: Nova Fronteira, 1994.

MARCONDES, Danilo; FRANCO, Irley. A filosofia: O que é? Para que serve? Zahar: Rio de Janeiro, 2011.

McCARTHY, Thomas. Private Irony and Public Decency: Richard Rorty's New Pragmatism. Critical Inquiry, v. 16, p. 355-370, 1990.

PRADO JÚNIOR, Bento. Alguns ensaios: filosofia, literatura, psicanálise. 2. ed. São Paulo: Paz e Terra, 2000.

RORTY, Richard. A filosofia e o espelho da natureza. Tradução de Antônio Trânsito. 2. ed. Rio de Janeiro: Relume-Dumará, 1993. sença, 1994.

Contingência, ironia e solidariedade. Tradução de Nuno Ferreira da Fonseca. Lisboa: Pre-

. Heidegger, Kundera, and Dickens. In: Essays on Heidegger and others: philosophical papers

II. Cambridge, UK: Cambridge University Press, 1995. p. 66-82.

The Inspirational Value of Great Works of Literature. In: Achieving our Country. Cambridge: Harvard University Press, 1997. p. 125-140.

. Truth and Freedom: a reply to Thomas McCarthy. Critical Inquiry, v. 16, p. 633-643, 1990.

Submetido em: 09/07/2015

Aceito em: 13/12/2015

Revista Letras, Curitiba, N. 92 p. 26-37, JUL/DEZ. 2015.

ISSN 2236-0999 (VERSÃo ELETRÔNICA) 